Observation and Simulation of Long-Period Ground Motions In the Persian/Arabian Gulf From Earthquakes in Zagros Thrust Belt

A. Pitarka, M. E. Pasyanos, R. J. Mellors, A. J. Rodgers

December 20, 2012 
This document was prepared as an account of work sponsored by an agency of the United States government. Neither the United States government nor Lawrence Livermore National Security, LLC, nor any of their employees makes any warranty, expressed or implied, or assumes any legal liability or responsibility for the accuracy, completeness, or usefulness of any information, apparatus, product, or process disclosed, or represents that its use would not infringe privately owned rights. Reference herein to any specific commercial product, process, or service by trade name, trademark, manufacturer, or otherwise does not necessarily constitute or imply its endorsement, recommendation, or favoring by the United States government or Lawrence Livermore National Security, LLC. The views and opinions of authors expressed herein do not necessarily state or reflect those of the United States government or Lawrence Livermore National Security, LLC, and shall not be used for advertising or product endorsement purposes.

This work performed under the auspices of the U.S. Department of Energy by Lawrence Livermore National Laboratory under Contract DE-AC52-07NA27344. 


\title{
Observation and Simulation of Long-Period Ground Motions In the Persian/Arabian Gulf From Earthquakes in Zagros Thrust Belt
}

\author{
Arben Pitarka, Michael E. Pasyanos, Robert J. Mellors, and Arthur J. Rodgers
}

\section{Table of Contents}

Summary

Task 3. Analysis of Long-Period Ground Motions in the Gulf............................................

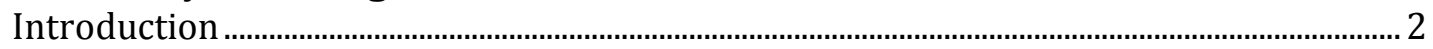

Recorded Spectral Response Characteristics .................................................................................... 6

Task 4. Modeling of Long-Period Ground Motions in the Gulf................................11

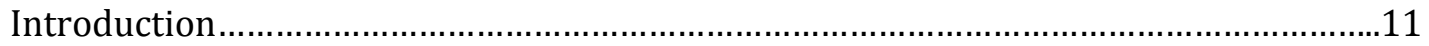

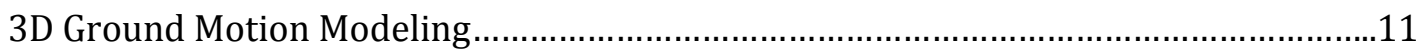

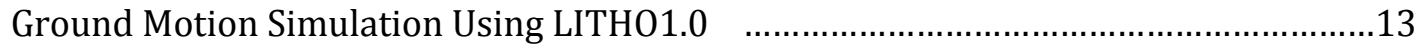

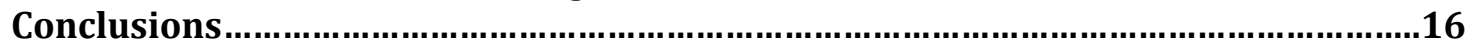

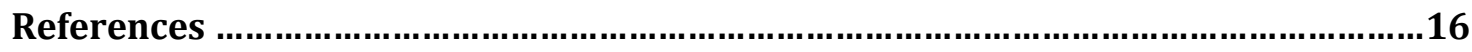




\section{Summary}

The Arabian Gulf is adjacent to one of the most seismically active fold-and-thrust belts on Earth, the Zagros Mountains. Broadband seismic records of earthquakes in the Zagros Mountains recorded on the Arabian side of the Gulf display long duration surface waves. While shorter periods $(<1 \mathrm{~s})$ are attenuated from crossing the deep sediments $(>10 \mathrm{~km})$ of the Gulf basin, the long period energy is relatively unaffected. Consequently large earthquakes in the Zagros could result in possibly damaging ground motions at long-periods $(1-10 \mathrm{~s})$. Such ground motions are of concern for large engineered structures, such as tall buildings and long bridges with resonant periods in the same frequency band (period of 1-10 s).

This study reports on two tasks, which were part of a larger study, intended to address these concerns. In Task 3, "Analysis of long period ground motions in the Gulf," we investigate some of the characteristics of ground motion recorded in the western shore of the gulf from selected earthquakes in the Zagros Mountains region. Exceptionally long-duration seismic waves, as compared with standard models, are shown to occur with periods of 1-10 seconds. This may be due to waveguide effects in the sedimentary basin. In Task 4, "Modeling of Long-Period Ground Motions in the Gulf," we performed 3D wave propagation simulations using finite difference calculations and four basin models, including a preliminary version of model LITH01.0, with different shallow sedimentary layer structures. The modeling results confirm our hypothesis that long period waves with extremely long duration and relatively large amplitudes are controlled by the geometry of the top basin sedimentary layers and source depth. Combined effects of basin edge geometry with sharp velocity contrast and shallow sources $(<10 \mathrm{~km})$ on the east part of the Arabian Gulf can cause large long period ground motion on the west part of the Gulf basin.

\section{Task 3. Analysis of Long-Period Ground Motions in the Gulf}

We will measure response spectra from available broadband recordings of earthquakes in the Gulf region. We will search for systematic variations in the amplitude and duration of shaking with source properties (e.g. depth, mechanism) and path propagation.

\section{Introduction}

In a recent study we demonstrated that the sedimentary geology of the Arabian Gulf causes higher amplitude and longer duration ground shaking then would be expected in more normal continental crustal structure. The most seismically active region near the Kingdom of Saudi Arabia is the Zagros Thrust Belt. Large (M> 6.0) events occur on average at least once a year or more frequently in this region; however, these events are $200 \mathrm{~km}$ or greater from the Arabian coast. Ground motion hazard for such large distances is unusual. Nonetheless, ground motions caused by 
distant events in the Zagros have resulted in felt motions in tall buildings in cities along the Arabian coast. An example of this is the November 22, 2005 M 5.7 Qeshm Island. This event caused motions in tall buildings in Dubai, United Arab Emirates, and other cities along the Gulf coast. The locations of earthquakes and seismic stations considered in this study are shown in Figure 1.

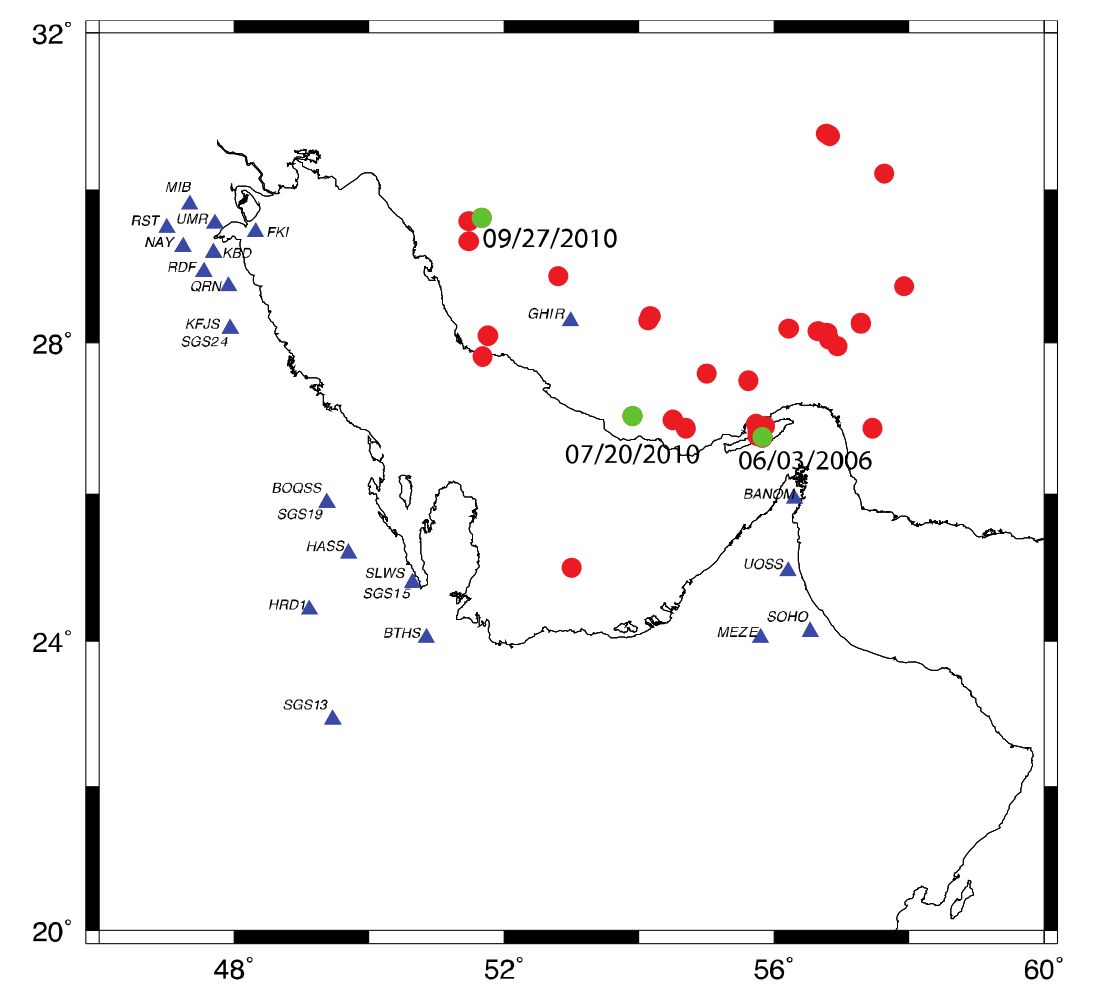

Figure 1. Map of study region showing earthquakes (circles) and seismic stations (triangles). Green circles show the location of three earthquakes considered in the comparisons of acceleration response spectra shown in Figure 6.

The Zagros Thrust Belt results from the collision of the Arabian Plate with the southern margin of Eurasia. This collision results in uplift of the Iranian Plateau and is evidenced by the high rate of seismicity along a broad northwest-southeast trending band. This zone marks one of the most intense regions of intra-continental seismicity on Earth. The nature of deformation across this zone is complex, involving both thrust and strike-slip as indicated by earthquake focal mechanisms (Telebian and Jackson, 2004). The Zagros experiences on average 5 earthquakes of magnitude 5.0 and greater each year

The Persian/Arabian Gulf (hereafter referred to simply as the Gulf), adjacent to the Zagros, is composed of a deep sedimentary basin. Sediments of the Arabian Platform dip eastward, reaching a depth of up to $10 \mathrm{~km}$ adjacent to the Zagros. Figure 2 shows a map of depth to basement in the region. The deep structure of the Gulf is composed of geologically old and consolidated sediments with moderately 


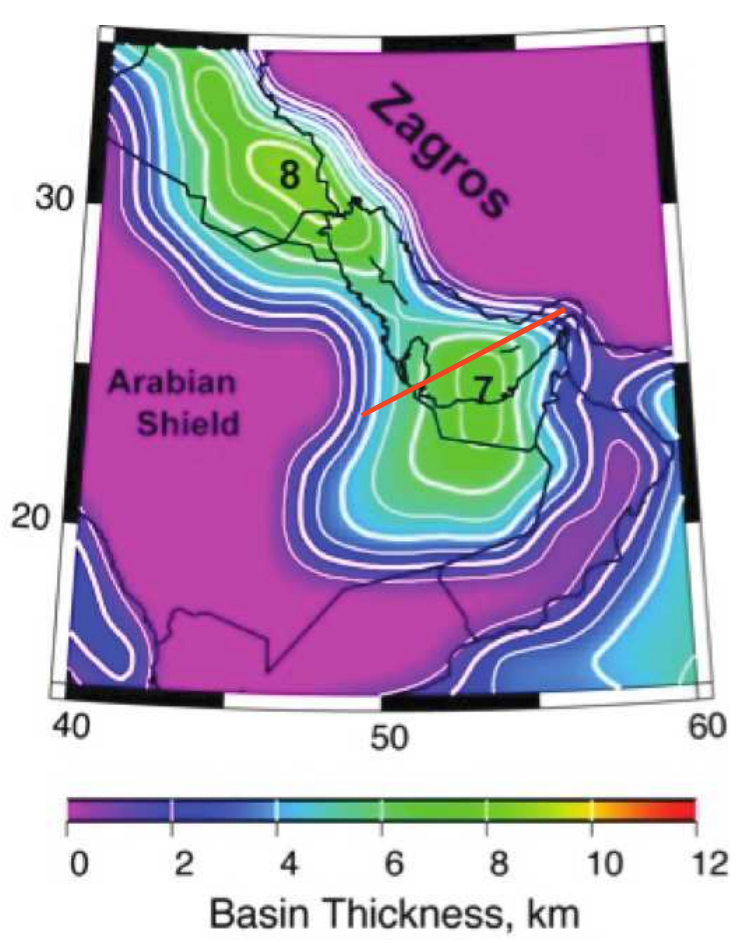

Figure 2. Sediment thickness of the Arabian Gulf and surrounding region. Red lines indicates the location of the cross section of the basin used in simulating basin structure effects.

high shear velocities (Pasyanos et al., 2012). However, the younger sediments near surface have much lower velocities and probably low attenuation.

This complex basin structure is of particular concern for earthquake hazard in the Gulf. Several large earthquakes in the Zagros have resulted in felt ground motions along the western coast of the Gulf. These events have been particularly strongly felt in high-rise buildings in the urban centers along the Gulf, such as Ad Dammam (Saudi Arabia), Kuwait City (Kuwait), Doha (Qatar), Abu Dhabi, Dubai and Sharjah (United Arab Emirates, UAE). This task seeks to provide a quantitative measurement of these ground motions using broadband seismic records. In particular, this project is concerned with long-period (1-10 seconds) ground motions observed in the western side of the Arabian Gulf from earthquakes in the Zagros Mountains and Iranian Plateau to the east of the Gulf.

Ground motion recorded at seismic stations in eastern Saudi Arabia from the M5.1 June 3, 2006 earthquake, located near Qeshm Island, were selected to illustrate this phenomenon (Figure3). The seismic response (north component, corresponding most naturally with the transverse component) is shown for two frequency (period) ranges: (a) 0.02-0.05 Hz (50-20 seconds) and 0.1-1.0 Hz (10-1 seconds). The longer period band (50-20 s) shows the surface waves arriving between 3.5 and $3.0 \mathrm{~km} / \mathrm{s}$, as expected for normal continental paths at regional distance. The surface wave is relative simple without an unusually long duration and is normally dispersed as 
(a)

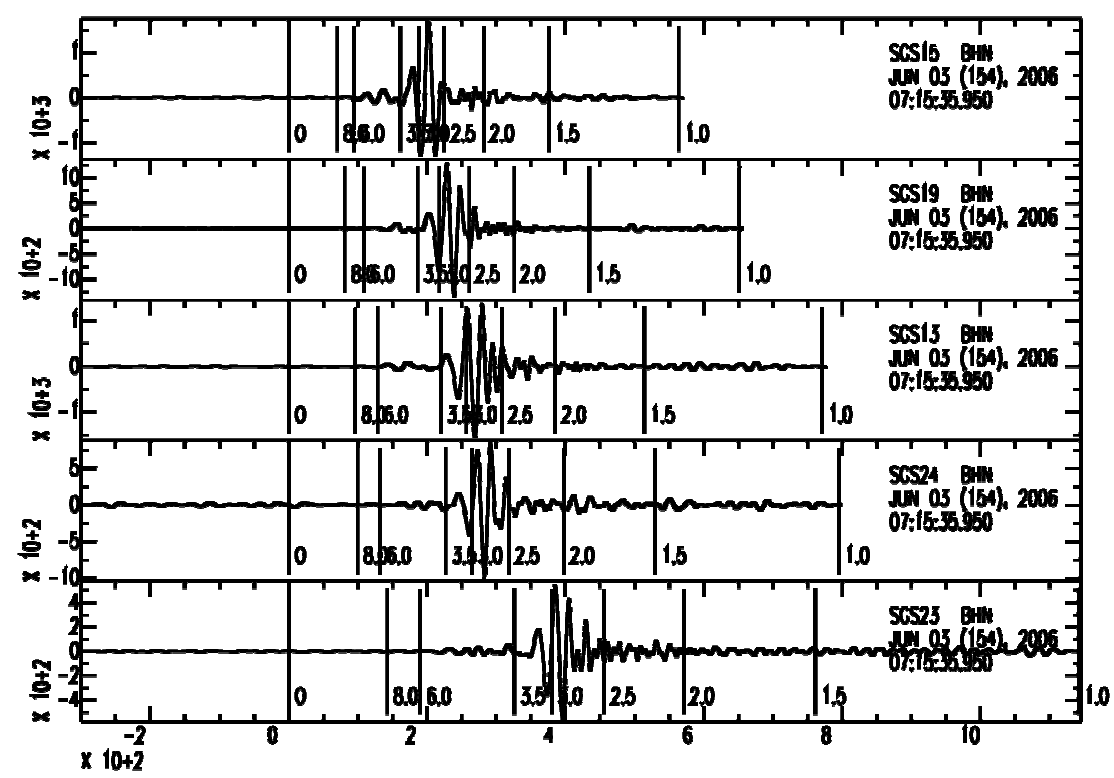

(b)

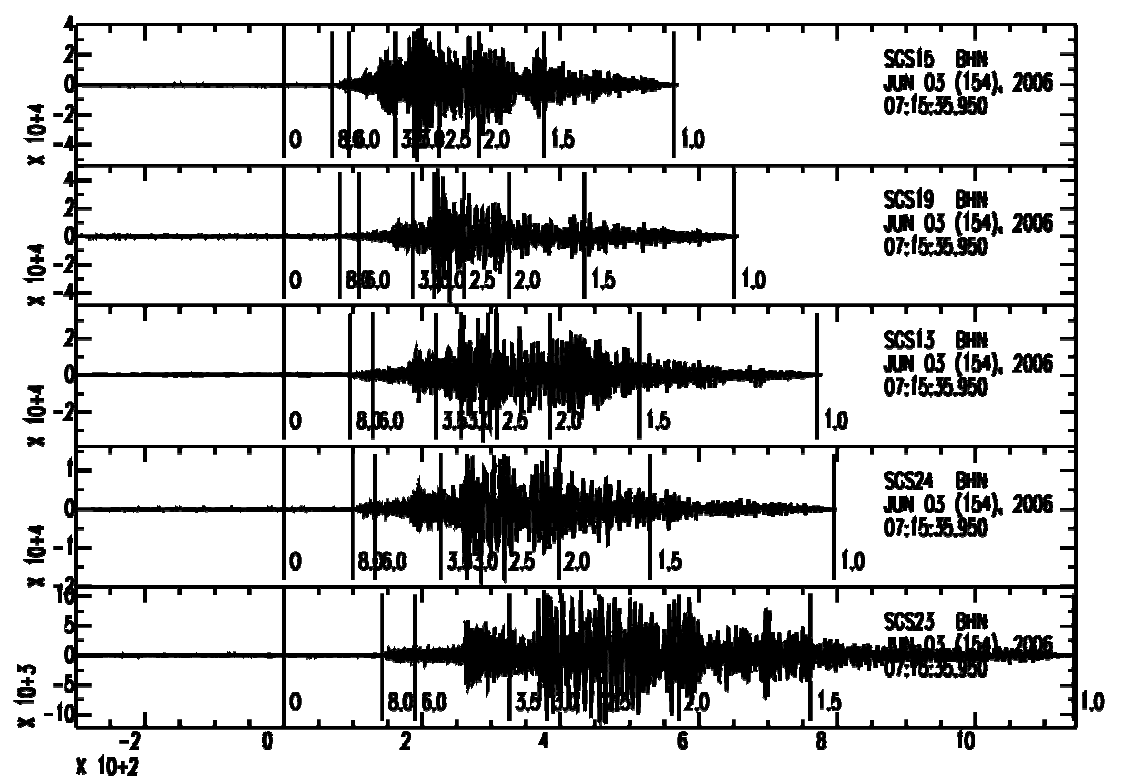

Figure 3. Seismograms for 3 June, 2006 earthquake recorded at stations in eastern Saudi Arabia filtered (a) $0.02-0.05 \mathrm{~Hz}$ (50-20 seconds) and (b) $0.1-1.0 \mathrm{~Hz}(10-1$ seconds). Each plot includes the group velocities in $\mathrm{km} / \mathrm{s}$. Note that the 10-1 second period band shows an usually long duration signal of more than 200 seconds in the group velocity window 3.0-1.5 $\mathrm{km} / \mathrm{s}$.

expected. However, at the shorter period the response shows an unexpectedly long duration of up to hundreds of seconds and at lower group velocities of $3.0-1.5$ $\mathrm{km} / \mathrm{s}$. This long duration shaking in the period band 1-10 seconds will cause increased loading on large engineered structures with sensitivity to this band. Similar observations have been made for other earthquakes recorded at station 
HASS for which the wave path goes through the thick sedimentary cover in the Persian/Arabian Gulf.

The observed extraordinarily long duration are likely due to a waveguide effect from the deep sedimentary structure which enhances long-period ground motion. Strictly speaking these motions are short-period surface waves, but are longerperiod ground motion that are normally observed and of concern for seismic hazard. This period range is of importance for evaluating earthquake ground motion hazards for large engineered structures with natural periods in the range 1-10 seconds, such as tall buildings, long bridges, and pipelines.

Seismic waveforms are affected by both path and source effects (e.g., Pitarka et al., 1998). Path effects are caused by varying material properties along the wave path. Differences in wave path for different source locations and depths cause variations in amplitude and duration, and are usually frequency dependent. Lateral and vertical variations in velocity cause dispersion, diffraction, and reflections, all of which affect wave amplitude and duration. The effect of wave scattering is significant at intermediate frequencies $(0.05-1 \mathrm{~Hz})$ as the waves propagate in the top sedimentary layers of the Gulf and eastern Arabian platform. Attenuation, which tends to affect higher frequencies more than lower frequencies, often is stronger in sedimentary basins than in older shield areas. Increased duration and relatively large amplitude of ground motion recorded along the western side of the Gulf region suggests that seismic attenuation is very low. The earthquake source itself varies both in focal mechanism and in depth, which also affects ground motion characteristics at all distances. Long-period ground motions are more likely to impact large structures because the resonant period of large structures is longer than small structures. It is the purpose of this report to investigate and understand the causes of these extraordinarily long duration surface waves for paths crossing the Arabian Gulf.

\section{Recorded Spectral Response Characteristics}

An effective tool in analyzing multiple seismic records of ground motion and their potential effects on buildings is the acceleration response spectrum. Here we show the spectral response at various locations as compared with two empirically derived ground motion prediction equations (GMPE): Campbell and Bozorgnia (2008) and Boore and Atkinson (2006), hereafter referred as CB08 and BA06. These equations are based on regressions of ground motion data from selected earthquakes around the world. They should be distinguished from the simulation-based models presented in Task 4. CB08 equation, a Next-Generation Attenuation (NGA) equation, was designed for active shallow crustal structures. It is controlled by various parameters, including earthquake magnitude, distance, type of rupture, and basin depth (depth to layer with Vs=2.5 $\mathrm{km} / \mathrm{s}$ ). Importantly, basin effects, as might be expected in the Gulf, are included. Because of the limited amount of good quality 
data the standard deviation of this equation is large at distances longer than $200 \mathrm{~km}$ and periods shorter than 3s. On the other hand AB06 is better constraint at large distances. It is developed for eastern North America, which in some respects resembles the sediments/shield structure of eastern Arabian Platform.

We compared the recorded spectral response with the two GMPEs. Figure 4 shows the spectral acceleration ratios of recorded and predicted ground motion using CB08 for the geometric mean horizontal component at periods $1 \mathrm{~s}, 5 \mathrm{~s}$, and $10 \mathrm{~s}$, and $5 \%$ damping. The predicted ground motion was computed for a depth to basement of $3.5 \mathrm{~km}$. The recorded motion is much higher than the one predicted by the GMPE at the period of $10 \mathrm{~s}$. It is comparable at the $5 \mathrm{~s}$ period and much lower at the $1 \mathrm{~s}$ period. Figure 5 shows the mean spectral acceleration ratios of recorded and predicted ground motion at periods $1 \mathrm{~s}, 5 \mathrm{~s}$, and 5\% damping computed using BA06.

The comparison with both GMPEs clearly shows that due to basin effects the ground motion is amplified significantly at periods $5 \mathrm{~s}$ and $10 \mathrm{~s}$. In contrast the ground motion is reduced significantly at 1 s periods.

Figure 6 illustrates the ground motion amplification along different wave paths, across the Gulf basin, for three earthquakes. We used recorded acceleration response spectra from the M5.3, 2006/06/03 earthquake, M5.7, 2010/07/20 earthquake, and M5.9, 2010/09/27 earthquake, at stations with good quality data in the Arabian Gulf region. When looking at the response spectra from the 2010/09/27 earthquake, the most striking feature is the difference in spectral amplitudes in the E-W component between station SGS15 and the rest of the stations. At SGS15 the E$\mathrm{W}$ spectral acceleration is much larger in the period range 0.5-4 s. In contrast, the spectral amplitudes at station SGS19, which has similar epicentral distance but located further to the north, are similar to those recorded by the other stations. The observed differences between SGS15 and SGS19 is a clear indication of very different wave propagation effects along paths across the basin. A similar trend is seen for the 2010/07/20 event located in the center of the Gulf region. Although the epicentral distance of SLWS is twice as large as that of UOSS the observed spectrum at this station is at least a factor of 10 larger especially in the period range of 1-10 s. The two stations stand on opposite wave paths with very different basin depths. UOSS located in the shallow part of the basin has a flat spectrum, whereas at SLWS the spectral amplitudes peak in the period range of $2-8 \mathrm{~s}$. Very similar spectral characteristics, apparently caused basin surface waves, are seen in the other two stations.

Based on these observations, we concluded that the deep sedimentary structure in the Gulf acts as a waveguide that enhances seismic wave amplification along paths that cross the basin. Therefore the knowledge of the basin structure is crucial in predicting strong ground motion in the western coast of the Gulf. 

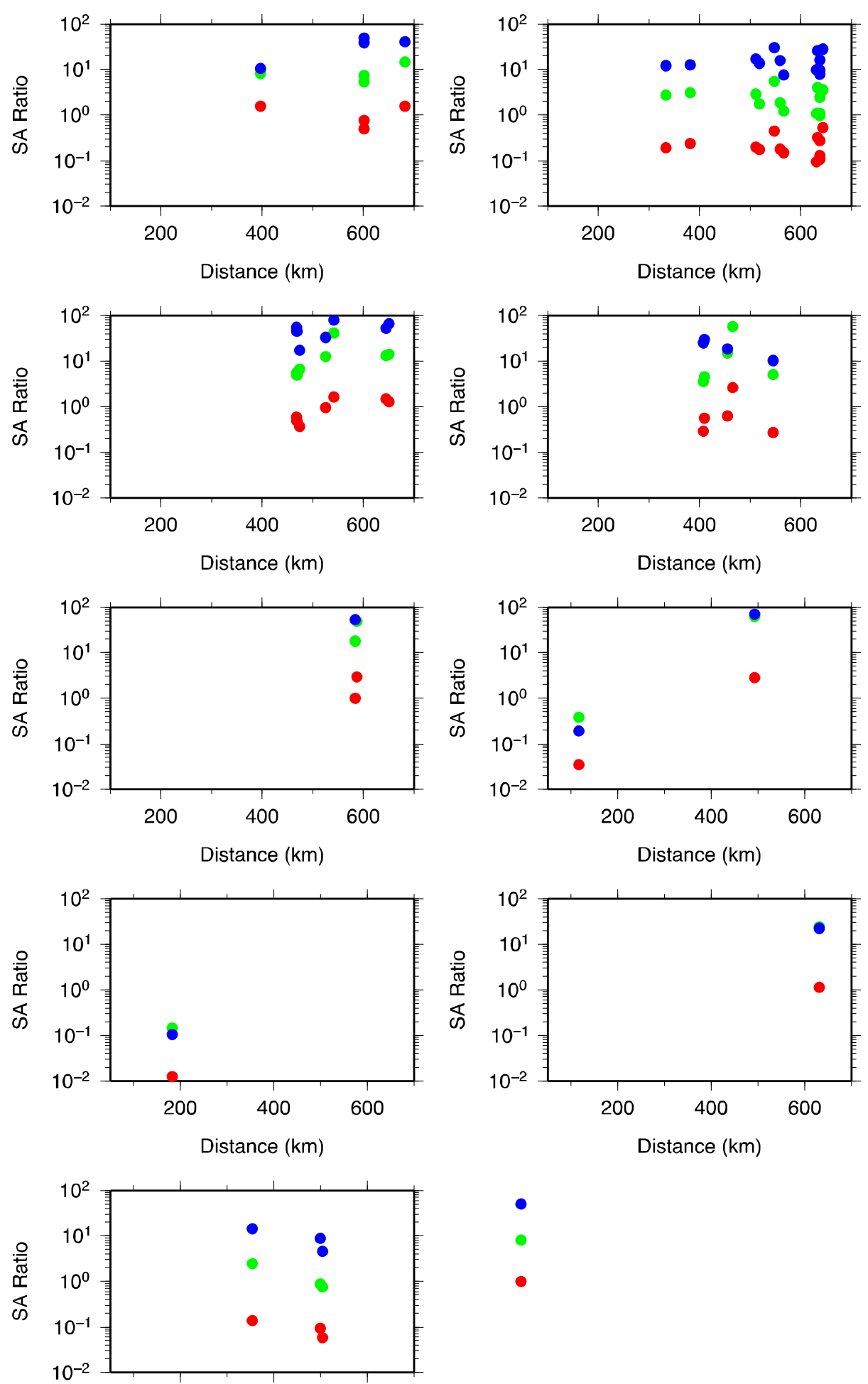

Figure 4. Spectral acceleration ratios of recorded and predicted ground motion for the geometric mean horizontal component at periods $1 \mathrm{~s}, 5 \mathrm{~s}$, and $10 \mathrm{~s}$, and $5 \%$ damping. The predicted ground motion was computed using the GMP of Campell and Bozorgnia (2008). The stations name is indicated in each panel. 

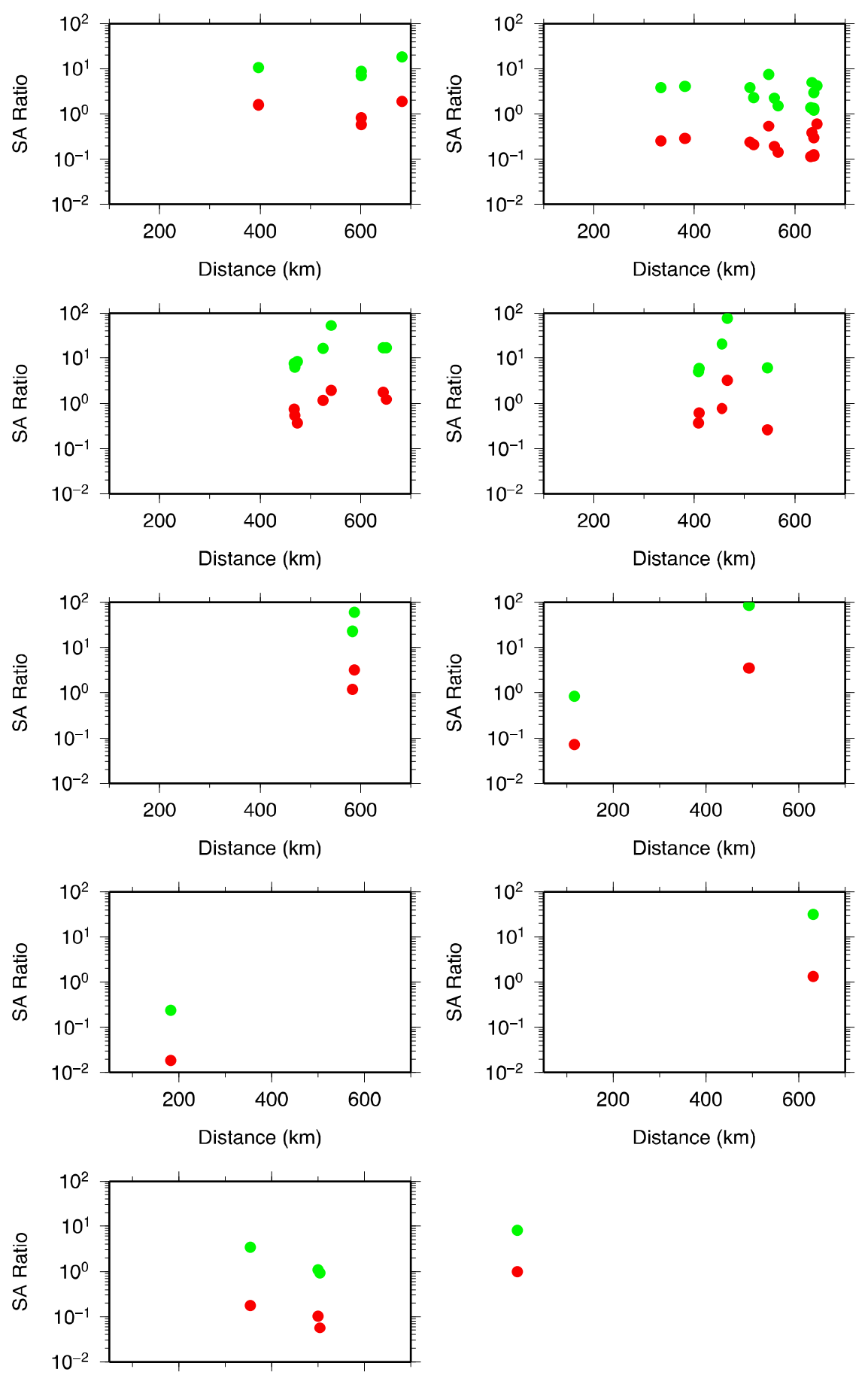

Figure 5. Mean spectral acceleration ratios of recorded and predicted ground motion at periods of $1 \mathrm{~s}, 5 \mathrm{~s}$, and $5 \%$ damping. The predicted ground motion was computed using the GMP of Atkinson and Boore developed for Eastern North America (2006). The stations name is indicated in each panel. 

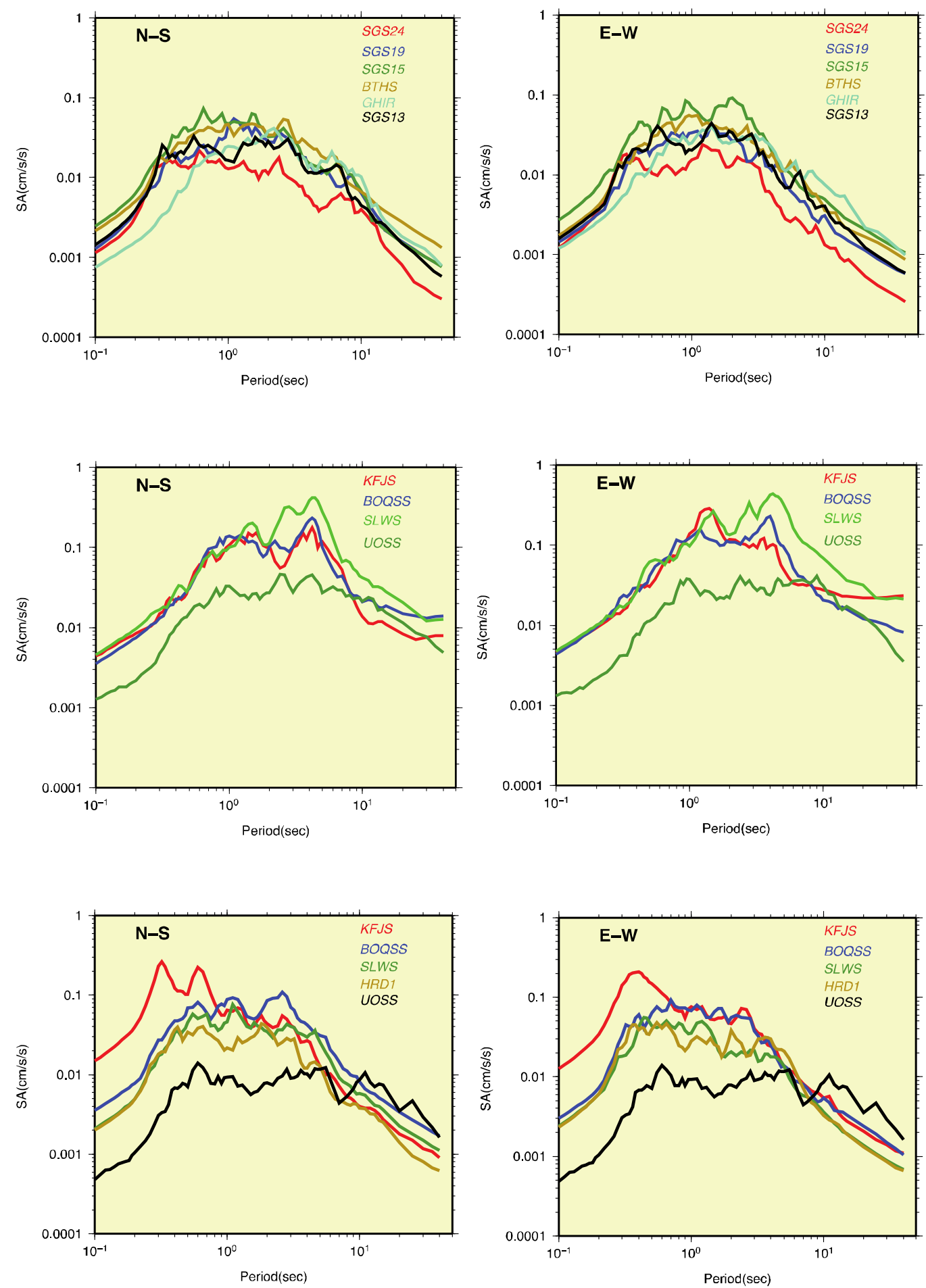

Figure 6. Acceleration response spectra for ground motion from M 5.3 2006/06/03 earthquake (top panels), M5.7 2010/07/20 (middle panels), M 5.9 2010/09/27 (bottom panels), recorded at different stations in the Gulf region. The names of the stations are shown in each panel. 


\section{Task 4. Modeling of Long-Period Ground Motions in the Gulf}

We will model long-period ground motions with the available models of $3 D$ crustal velocity and attenuation structure. We will use source parameters from events determine earlier in the project. Simulations of observed seismograms will be performed on highperformance computers at LLNL. We will port codes to high-performance computers at $K S U$.

\section{Introduction}

In order to understand the nature of the long-duration and increased amplitude of ground motion in the Gulf basin, we simulated wave propagation in threedimensional earth models using a finite-difference technique. In the future we plan to use validated velocity models such as LITHO1.0 to compute strong ground motion for large scenario earthquakes in the region.

We modeled elastic seismic wave propagation by using WPP, a computer code developed at Lawrence Livermore National Laboratory (Petersson and Sjogreen, 2010a). WPP is an anelastic finite difference code based on a second? order accurate scheme (Nilsson et al., 2007) including mesh refinement (Petersson and Sjogreen; 2010b) and a boundary conforming grid for the topographic free surface boundary condition (Appelo and Petersson , 2008). The code is designed specifically for use on massively parallel machines and has the capability to handle complex topography. WPP has been tested and validated against other numerical techniques, and has been used to model ground motion from large earthquakes in California, such as the 1906 San Francisco earthquake (Aagaard et al., 2008).

The preliminary 3D seismic velocity models used here are based on 2D cross sections of the sedimentary basin thickness reported by Laske and Masters (1997). Figure 7 shows cross sections of three basin velocity models. In Model 1 the surface sedimentary layer continues across the entire model. In Model 2 the surface sedimentary layer has limited extension toward the west. In Model 3 the geometry of the eastern basin edge is modified so that it can better channel the seismic energy coming from the seismic source below. Al three geometries represent possible characteristics of the basin structure in the Gulf region, which are not well resolved in current basin models. The multiple realizations of the basin geometry and different spatial extensions of surface sedimentary layers in 3D ground motion simulations can improve our understanding of the influence of the sedimentary basin structure on seismic waves propagation in the Arabian Peninsula. Our goal is to replicate both the frequency response and the duration of the observed seismograms using our modeling techniques. 

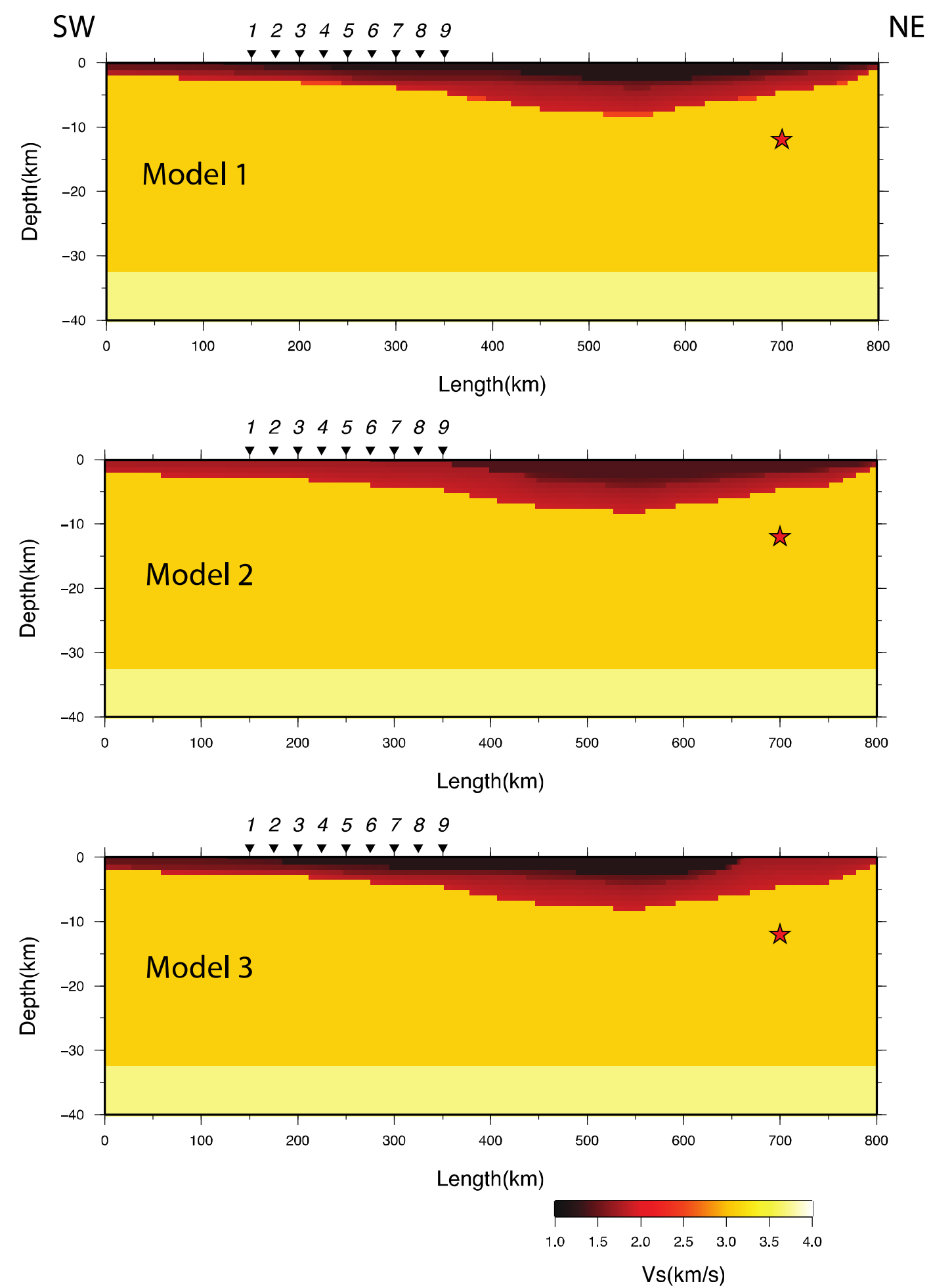

Figure 7. Vertical cross sections of three velocity models used in the simulation of basin generated waves. Star indicates the location of the double couple point source. 


\section{D Ground Motion Simulation}

3D ground motion simulations at periods of practical interest and for large regions require massive parallel computing. In this study the maximal modeled frequency is $0.4 \mathrm{~Hz}$. We used a grid spacing of $200 \mathrm{~m}$ in the top $10 \mathrm{~km}$ of the model, and $400 \mathrm{~m}$ in the region below $10 \mathrm{~km}$. All simulations with WPP code were performed on 500 computer nodes.

Figure 8 shows synthetic velocity seismograms computed for a Mw5.4 double couple point source with a thrust mechanism using Model 1, Model 2, and Model 3. The top sedimentary layer in our velocity models has a $V p=2.2 \mathrm{~km} / \mathrm{s}, \mathrm{Vs}=1.2 \mathrm{~km} / \mathrm{s}$, density $2 \mathrm{~g} / \mathrm{cm}^{3}, \mathrm{Qp}=200$ and $\mathrm{Qs}=100$. The source depth is $12 \mathrm{~km}$. We used a Gaussian source time function with predominant frequency of $1 \mathrm{~Hz}$. Note that only stations 1 and 2 have epicentral distances over $500 \mathrm{~km}$. Their epicentral distance is in the range of distances of stations located on the west side of the Gulf from earthquakes in the Zagros region. The simulations reproduce the duration of the ground motion observed at such distances. The duration of the simulated ground motion increases with distance, and the basin-trapped waves are clustered in different wave trains that relate with different basin layers in our model. Here we focus on long period waves. We band-pass filtered the synthetic seismograms in two frequency ranges $0.1-0.4 \mathrm{~Hz}(2.5 \mathrm{~s}-10 \mathrm{~s}$ period range) and $0.02-0.05 \mathrm{~Hz}(20 \mathrm{~s}-50 \mathrm{~s}$ period range). The comparisons between the three models in two frequency ranges are shown in Figures 9a and 9b. The long period surface waves (20-40 s) are only affected by the deep basin structure. They are very similar for all models. The effect of structural complexities in the shallow basin sedimentary layers is observed at relatively short periods, especially in the vertical component of motion (Figure 10). The differences among the basin models become significant at station 1 and 2 which record waves that travels across the entire basin structure. These simulations illustrate the significant effect of shallow sedimentary layers on ground motion duration and amplitude in the period range of $2.5 \mathrm{~s}-10 \mathrm{~s}$.

\section{Ground Motion Simulation Using LITHO1.0}

Simulations were run through a preliminary version of the velocity model LITH01.0 (Pasyanos et al., 2012). The LITH01.0 is an update of the crustal models CRUST5.1 (Mooney et al., 1998) and CRUST2.0 (Bassin et al., 2000), but at higher $\left(1^{\circ}\right.$ ) resolution and extended deeper into the mantle to include the lithospheric lid and asthenosphere layers. Unlike the previous models, it is driven by its ability to fit a recently developed high-resolution surface wave dispersion model (Ma et al., 2012) which includes both Love and Rayleigh, and both group and phase velocity, over a wide frequency band ( $5 \mathrm{mHz}-40 \mathrm{mHz}$ ). Sedimentary structure, which is important for the simulations presented here, are derived from the $1^{\circ}$ sediment model of Laske and Masters (1997). Although the shear wave velocity of the basin sedimentary layers in the original LITHO1.0 model is as low as $525 \mathrm{~m} / \mathrm{s}$ near the free surface, in our simulations we limit the shear wave velocity to $1200 \mathrm{~m} / \mathrm{s}$. Using a minimum 

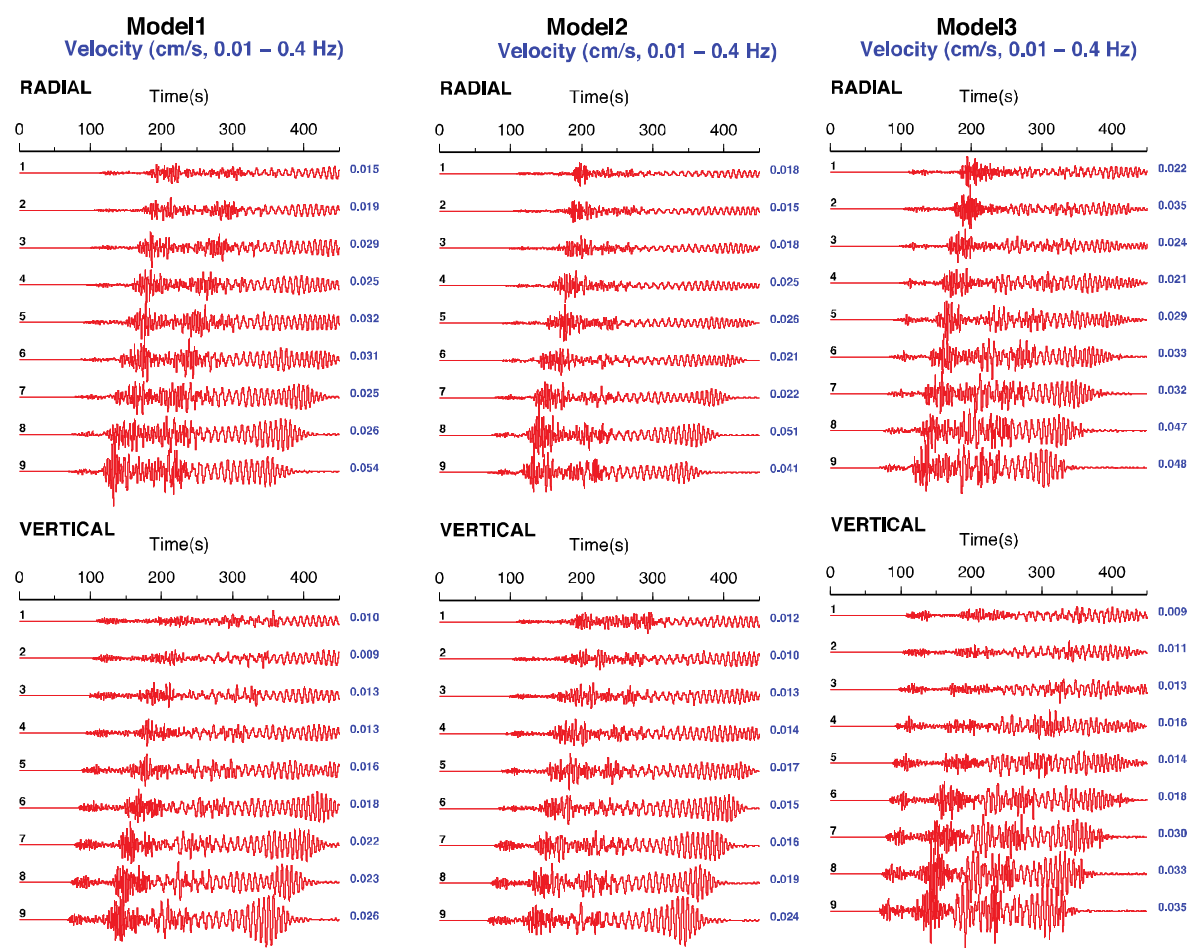

Figure 8. Synthetic velocity seismograms computed for a double couple point source with a thrust mechanism using Model 1 (left panels) Model 2 (central panels), and Model 3 (right panels). The seismograms are band-pass filtered at 0.01-0.4 Hz.
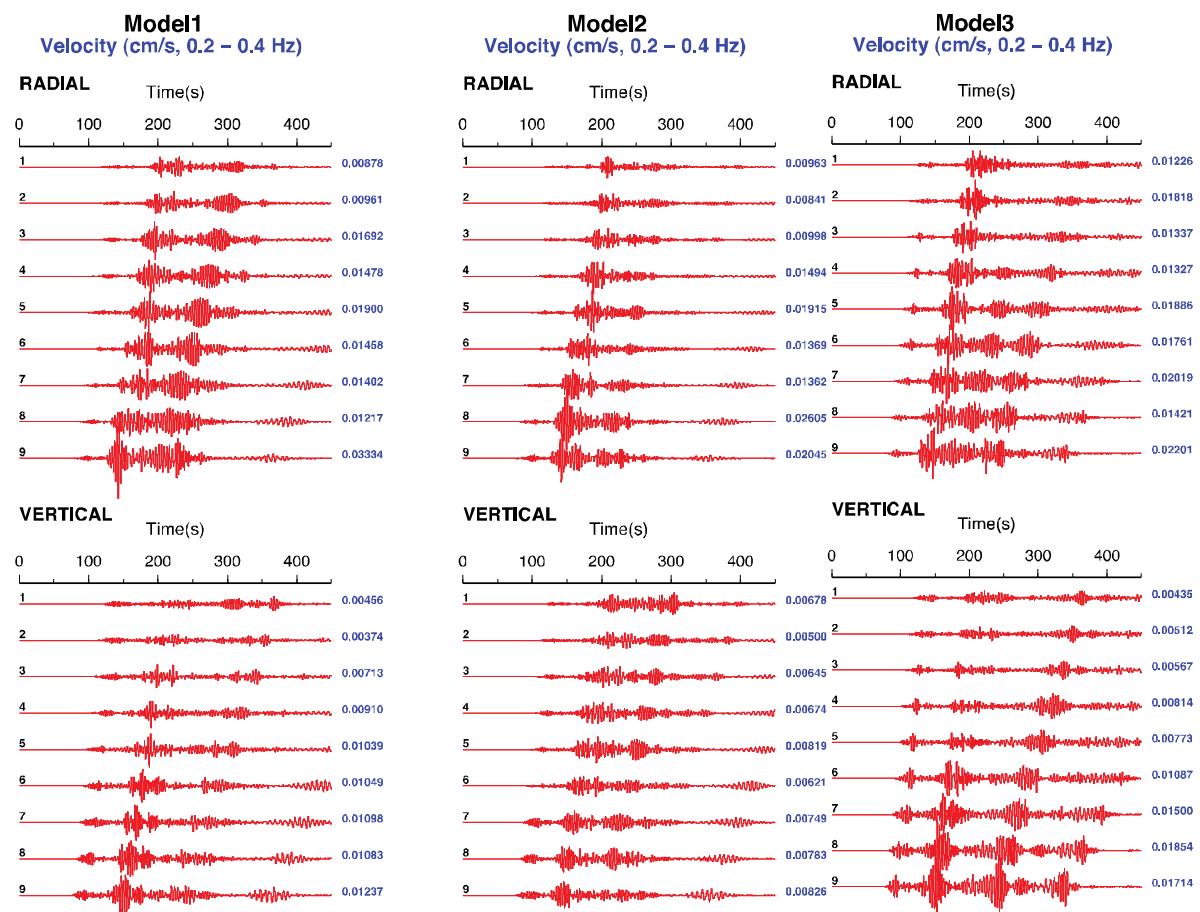

Figure 9a. Synthetic velocity seismograms computed for a double couple point source with a thrust mechanism using Model 1 (left panels) and Model 2 (central panels), and Model 3 (right panels). The seismograms are band-pass filtered at $0.2-0.4 \mathrm{~Hz}$. 

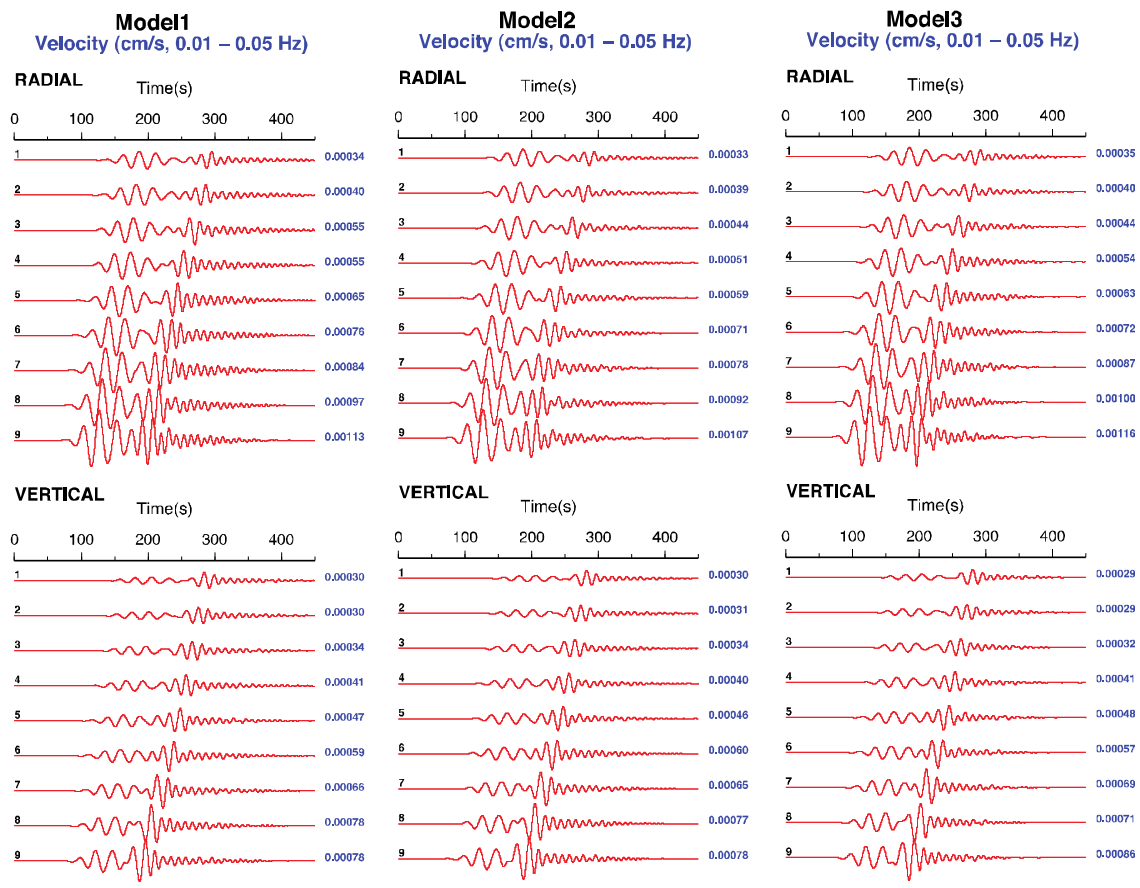

Figure 9b. Same as 9a, but band-pass filtered at 0.01-0.05 Hz.

grid spacing of $200 \mathrm{~m}$ the corresponding maximal modeled frequency is $0.4 \mathrm{~Hz}$. A vertical cross-section of the model is shown in Figure 11. The increase of shear wave velocity in the top sedimentary layers decreases both the amplitude and duration of basin secondary waves. This is mainly caused by the weakening of the wave trapping mechanism caused by the reduction of the velocity contrast between shallow and deeper sedimentary layers.

Figure 12 shows the synthetic ground motion computed with LITH01.0. LITH01.0 produces ground motion waveforms that are similar to ones simulated with Model1. The most significant differences between the two models are seen at short periods 1-3s for which LITH01.0 produces much larger ground motion (see response spectra in Figure 13). LITHO1.0 produces ground motion that is consistent with the observed ones. For example the shape of response spectra at station 1 and 3 which correspond to station SGS 13 and BTHS for the M5.3, 2006/06/03 earthquake, compare well with spectra of E-W component (see Figure 6).

\section{FDM Computer Program}

The 3D-FDM WPP computer program used in our simulations was installed and put into operation on the computer system of the King Saud University on December 2012. 


\section{Conclusions}

Comparisons with two commonly used GMPEs performed in Task 3 showed that ground motion recorded in the Gulf region from earthquakes in the Zagros region is highly anomalous. The recorded peak ground motion is much higher than the predicted one in the period range 1-10s. The extraordinary duration of the seismic energy in this frequency band may have a significant impact on large structures along the Gulf shoreline. We speculate that both duration and amplitude of the ground motion is due to waveguide effects in the sedimentary structure of the Gulf basin.

This hypothesis was tested in Task 4 using large-scale 3D waveform modeling and different basin models, including the recently developed model LITH01.0. Sensitivity analysis of the basin induced waves and the corresponding response spectra due to complexities in the shallow basin structure reveal the significance of 3D basin models in predicting strong ground motion in the Gulf region. Our simulations suggest that a plausible explanation of the anomalous observed ground motion is the generation of basin reverberation waves that are trapped in the shallow sedimentary layers of the basin. We also found that in order to explain the very large duration of ground motion the quality factors $Q p$ and $Q s$ in the top sedimentary layers should be at least 200 and 100 , respectively.

Since we focused on ground motion at very large distances, our simulations were performed using point source representation. Future simulations of well-recorded earthquakes in the Gulf region should use LITHO1.0 model and kinematic rupture models of earthquake sources. A better representation of the shallow crustal structure and source process will improve the quality of the ground motion simulation on a broad period range.

\section{References}

Aagaard, B., et al. (2008), Ground motion modeling of the 1906 San Francisco earthquake II: Ground motion estimates for the 1906 earthquake and scenario events, Bull. Seismol. Soc. Am., 98, 1012 1046,doi:10.1785/ 0120060410 .

Al-Amri, A.M. A. J. Rodgers, and T. A. Al-Khalifah (2008). Improving the level of seismic hazard parameters in Saudi Arabia using earthquake location. Arab J Geosci.

Appelo, D., and N. A. Petersson (2008), A stable finite difference method for the elastic wave equation on complex geometries with free surfaces, Commun. Comput. Phys., 5, 84-107. 
Bassin, C. G. Laske, and G. Masters (2000). The current limits of resolution in surface wave tomography in North America, EOS Trans. AGU, F897, 81.

Boore and Atkinson (2006), Earthquake Ground-Motion Prediction Equations for Eastern North America. Bull. Seism. Soc. Am., 96, no6, 2181-2205.

Campbell and Bozorgnia (2008) NGA ground motion model for the geometric mean horizontal component of PGA, PGV,PGD and 5\% damped linear elastic response spectra for periods ranging from 0.01 to $10 \mathrm{~s}$. Earthquake Spectra, 24, No1, 139-171.

Laske, G. and T.G. Masters (1997). A global digital map of sediment thickness, EOS Trans. AGU, 78, F483, http://igppweb.ucsd.edu/ gabi/sediment.html

Ma, Z. et al (2012). In preparation

Mellors, R. J.,V. E. Camp, F.L. Vernon, A.M. Al-Amri, and A. Ghalib (1999). Regional waveform propagation in the Arabian Peninsula.

Mooney, W.D., G. Laske, and G. Masters (1998). CRUST5.1: A global crustal model at $5^{\circ} \times 5^{\circ}, \mathrm{J}$. Geophys. Res., 103, 727-747.

Nilsson, S., N. A. Petersson, B. Sjogreen, and H.-O. Kreiss (2007), Stable difference approximations for the elastic wave equation in second order formulation, SIAM J. Numer. Anal., 45, 1902-1936, doi:10.1137/060663520.

Pasyanos, M.E., T.G. Masters, G. Laske, and Z. Ma (2012). LITHO1.0: An updated crust and lithospheric model of the Earth, in preparation.

Petersson, N. A., and B. Sjogreen (2010a), Reference guide to WPP version 2.0, Tech Rep. LLNLOTR?422928, Lawrence Livermore Natl. Lab., Livermore, Calif.

Petersson N.A., and B. Sjogreen (2010b). Stable grid refinement and singular source discretization for seismic wave simulations. Communications in Computational Physics, vol. 8, no. 5, pp. 1074-1110.

Pitarka, A., K. Irikura, T. Iwata and H. Sekiguchi (1998). Three-dimensional simulation of the near-fault ground motion for the 1995 Hyogo-ken Nanbu (Kobe), Japan, earthquake. Bull. Seism. Soc. Am., 88, 428-440.

Rodgers, A. J., N. A. Petersson, and B. Sjogreen (2010). Simulation of topographic effects on seismic waves from shallow explosions near the North Korean nuclear test site with emphasis on shear wave generation. Bull. Seism. Soc. Am., 115,B11309. 
Rodgers, A.J, A. Fowler, A.S. Al-Amri, and A. Al-Enezi (2006). The March 11, 2002 Masafi, United Arab Emirates earthquake: Insights into the seismotectonics of the northern Oman Mountains. Tectonophysics, 415 (2006) 57-64.

Rodgers, A.J. , J.F. Ni, and T. M. Hearn (1997). Propagation characteristics of shortperiod Sn and Lg in the Middle East, Bull. Seism.Soc. Am. 87, 396-413

Talebian, M., and J. Jackson (2004), A reappraisal of earthquake focal mechanisms and active shortening in the Zagros mountains of Iran, Geophys. J. Int., 156, $506-526$.
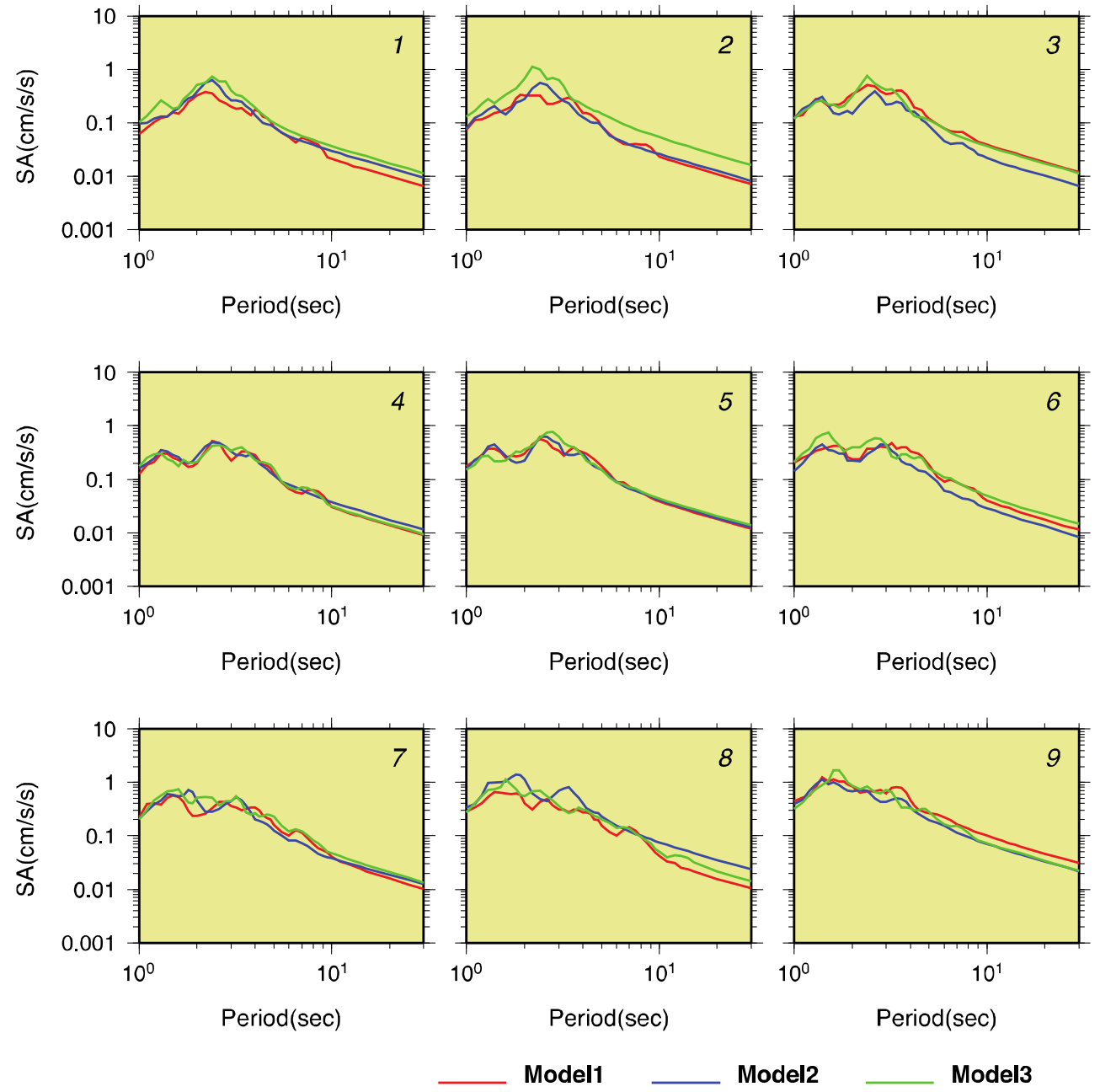

Figure 10. Comparison of acceleration response spectra of synthetic seismograms shown in Figure 8 for Model 1 (red traces), Model 2 (blue traces), and Model 3(green traces). 


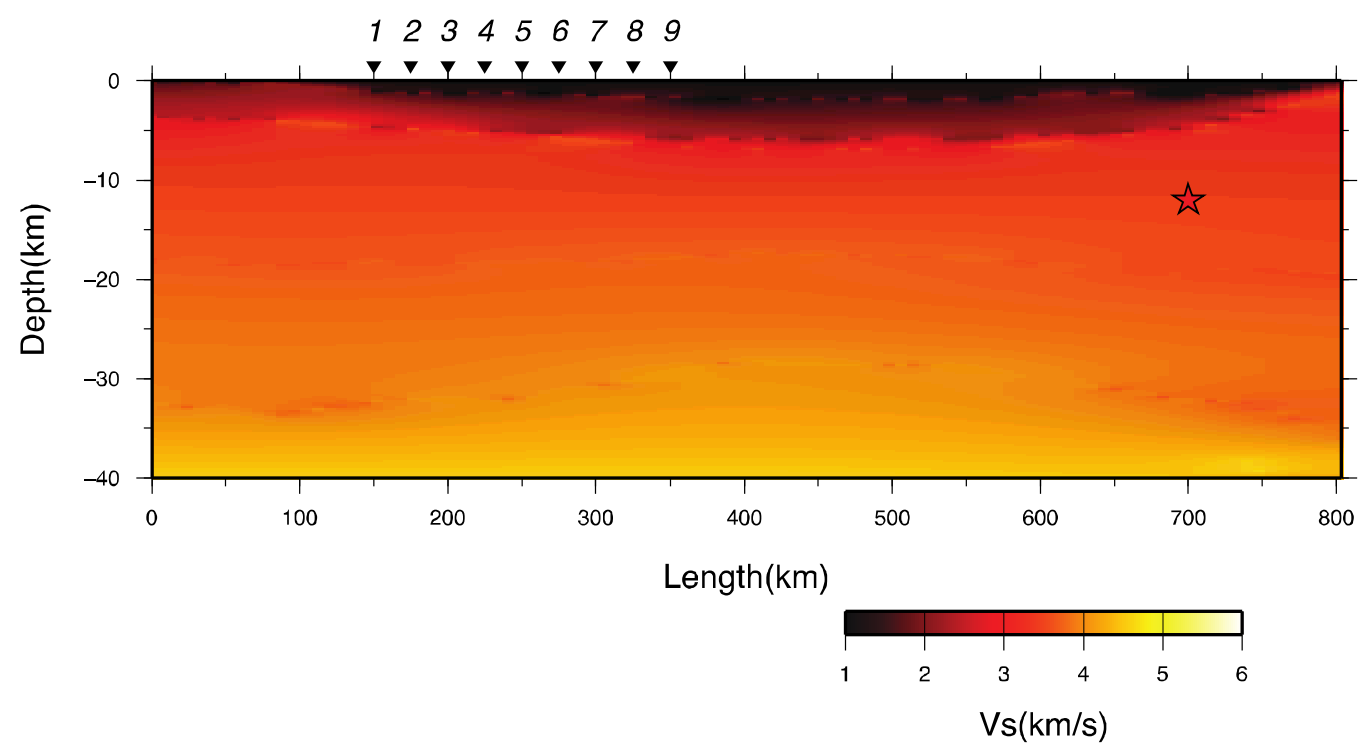

Figure 11. Vertical cross section of the tomographic model used in the simulation of basingenerated waves.
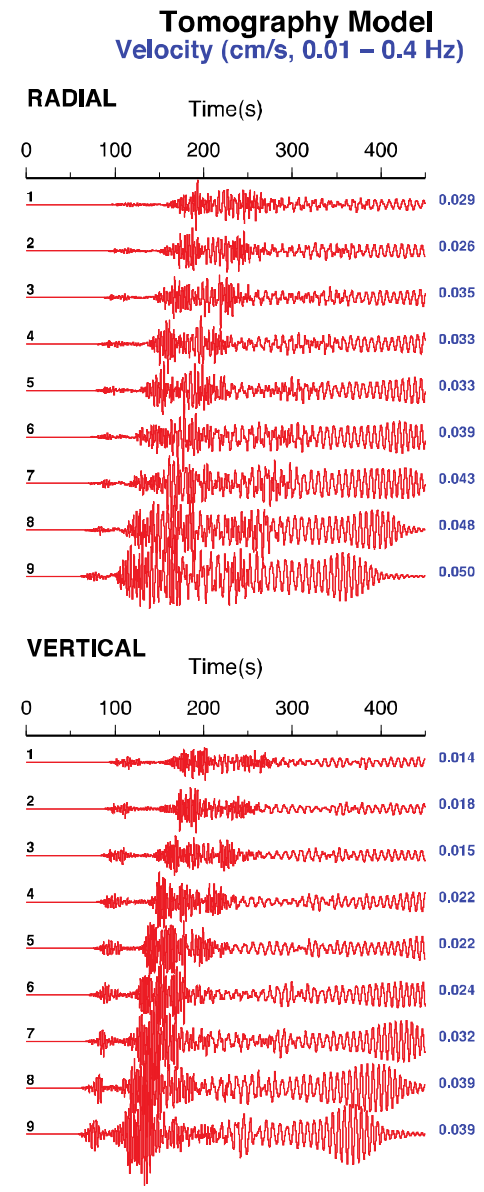

Figure 12. Synthetic velocity seismograms computed for a double couple point source with a thrust mechanism using tomographic model. 

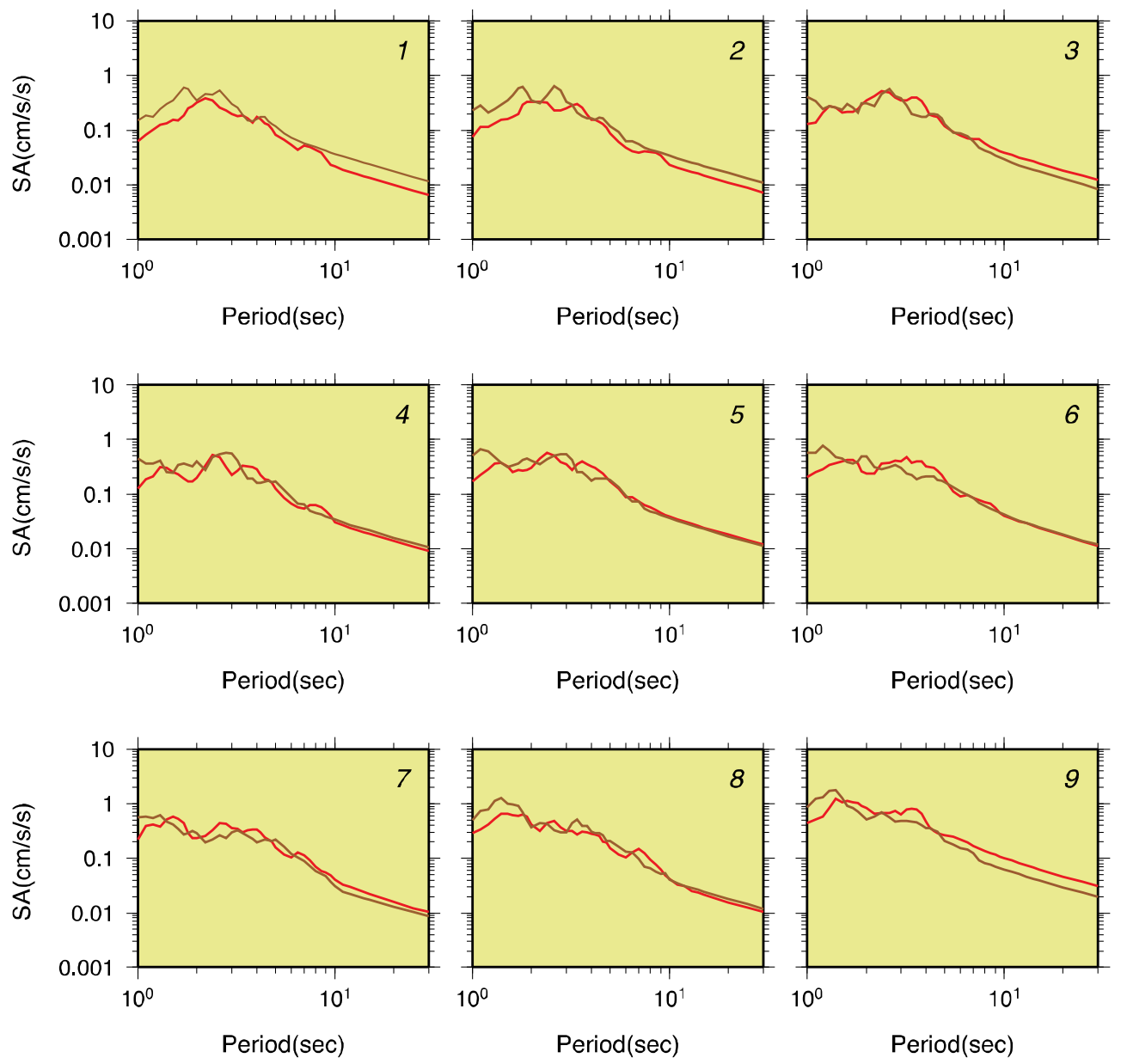

Model1

LITHO1.0

Figure 13. Comparison of acceleration response spectra of synthetic seismograms computed with the tomographic model and three other basin models. 